\title{
Implementation of AC to DC converter Using Thyristor in ATP
}

\author{
Sudeep Pyakuryal ${ }^{1}$, Mohammad Matin ${ }^{2}$ \\ ${ }^{l}$ Department of Electrical and Computer Engineering, University of Denver \\ ${ }^{2}$ Department of Electrical and Computer Engineering, University of Denver
}

\begin{abstract}
Silicon diodes are widely used for converting ac power into dc power. Diodes start conducting when they are forward biased and start producing dc voltage at the output but the output voltage is uncontrolled. With the use of a thyristor, instead of a diode, the output voltage can be controlled to a desired level. A thyristor needs a triggering pulse at the gate, when forward biased, to conduct. By controlling the triggering (firing) angle, the output dc voltage can be controlled effectively. A single phase full-wave controlled bridge ac to dc converter, rectifier, using thyristors is presented in this paper. Behavior of rectifier feeding different kinds of loads is investigated. To obtain the voltage and current waveforms, a program called ATP, Alternative Transients Program, has been utilized. ATP is world's most widely used electro-magnetic transients program and is available for use to the licensed users free of charge. In this paper, for a phase-controlled thyristor based rectifier, it has been shown that the average value of dc output voltage is controllable and is a function of triggering angle.
\end{abstract}

Keywords: AC to DC converter, ATP, Phase control, Rectifier, Thyristor

\section{Introduction}

Present day power electronic semiconductor switches with increased power capability, reduced cost, and increased controllability have made power converters cost effective solution for a number of power conversion applications. To understand the applicability of these power converters, it is necessary to understand the voltage and current capability of currently available power electronic switches. Power electronic semiconductor switches can be classified into following two groups according to their degree of controllability:

1. Uncontrollable- Diodes

2. Controllable- Thyristors

The controllable switches category includes several device types including bipolar junction transistors (BJTs), metal-oxide-semiconductor field effect transistors (MOSFETs), and insulated gate bipolar transistors (IGBTs). Some of these are suitable for low power and low voltage application, while some of these are suitable for high power and high voltage application.

Power electronics and semiconductor power switches in fact can be defined as a branch of electrical engineering that deals with conversion and control of electric power. It is estimated that at least half of the electric power generated in the USA flows through power electronic converters and an increase in this share to almost $100 \%$ is expected in the following few decades [1].

Block diagram of electric power conversion is shown in Fig. 1 [1]. It can be seen from Fig. 1 that a power converter converts constant magnitude and frequency input to a variable magnitude and/or frequency output.

As shown in Fig. 1, ac-to-dc conversion is accomplished using rectifiers. Rectifiers find wide-range of application in industries, transportation, power transmission, and so on

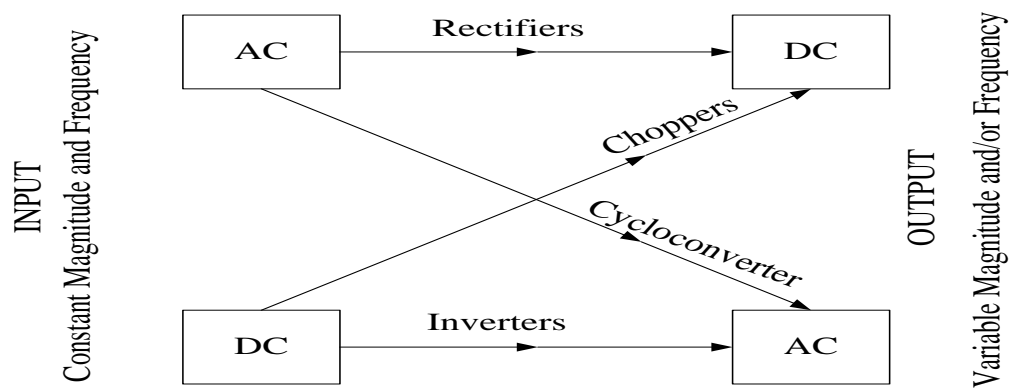

Figure 1. Electric power conversion 
The silicon diodes are widely used for rectifiers. It is well known fact that a diode starts conduction as soon as its anode to cathode voltage exceeds the threshold voltage when the diode is forward biased. But rectifiers with diodes are not controllable. In some application such as battery charger, it is necessary for the dc voltage to be controllable. When the diodes are replaced by thyristors, conduction does not happen merely after exceeding the threshold voltage when forward biased but also they need a triggering signal at the gate. Anode, cathode, and gate of a thyristor are sown in Fig. 2.

A thyristor controlled rectifier works as an uncontrolled diode rectifier when the firing angle, $\alpha$, of thyristor is zero. Therefore, in this paper, diode converts are not presented. Uncontrollable diode rectifiers are a subset of the controlled rectifiers. By the use phase control, average values of load voltage can be controlled and varied [2]. The application of triggering pulse at the thyristor gate at any desired instant during the period when the thyristor is forward biased to control the magnitude of the dc output voltage is called phase control [3]. Unless otherwise specified, a firing angle, $\alpha$, of $45^{\circ}$ is used in this paper.

The system being investigated in this paper is single-phase full-wave controlled bridge rectifier. Circuit diagram, mathematical expressions, and voltage and current waveforms are presented for each rectifier when feeding the following loads:

1. Resistive load, $\mathrm{R}$

2. Resistive, $\mathrm{R}$, and inductive, L, load

3. Resistive, R, Inductive, L, and EMF

The load electro-magnetic force, EMF, may be either a battery or back emf of a dc motor. Alternative Transients Program, ATP, has been used to model the system and obtain the waveforms [4].

\section{Rectifier With R Load}

Fig. 2 shows a single-phase bridge rectifier with $\mathrm{R}$ load. Anode, cathode, and gate are marked for thyristor T1. Similar is true for thyristors T2, T3, and T4. Once thyristor is fired at gate, while it is forward biased, thyristor starts conducting. Thyristor turns off when current being conducted reaches zero value.

$\mathrm{Vs}$ is root mean square, RMS, value of source voltage and Vo is average dc output voltage. Vs is given by $\mathrm{Vm}$ $\sin \omega t$ where $\mathrm{Vm}$ is peak value of Vs.

In the circuit shown in Fig. 2, T1 and T2 are fired simultaneously at firing angle, $\alpha$, in positive half cycle of the source. Similarly, T3 and T4 are fired simultaneously at firing angle, $\pi+\alpha$, in negative half cycle. Since the load is purely resistive, the voltage and current both go to zero at $\pi, 2 \pi$, and so on.

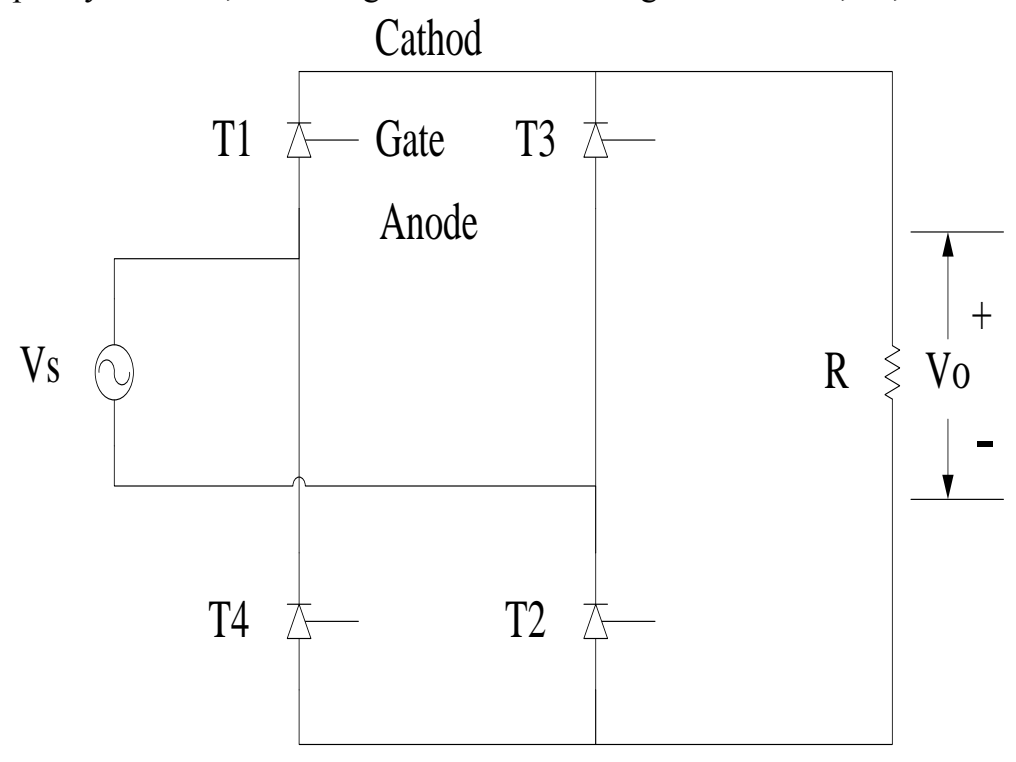

Figure 2. Single-phase full-wave bridge rectifier with R load

The source voltage and triggering signals are shown in Figure 3a. It can be seen that one cycle of the supply is $16.667 \mathrm{~ms}$ i.e. the supply frequency is $60 \mathrm{~Hz}$. Positive cycle is fired at $2.0833 \mathrm{~ms}$ i.e. at $45^{\circ}, 2 \pi+45^{\circ}$, $4 \pi+45^{\circ}$, and so on. Similarly negative half cycle is fired at $10.4167 \mathrm{~ms}$ i.e. at $180^{\circ}+45^{\circ}, 2 \pi+180^{\circ}+45^{\circ}$, $4 \pi+180^{\circ}+45^{\circ}$, and so on. 


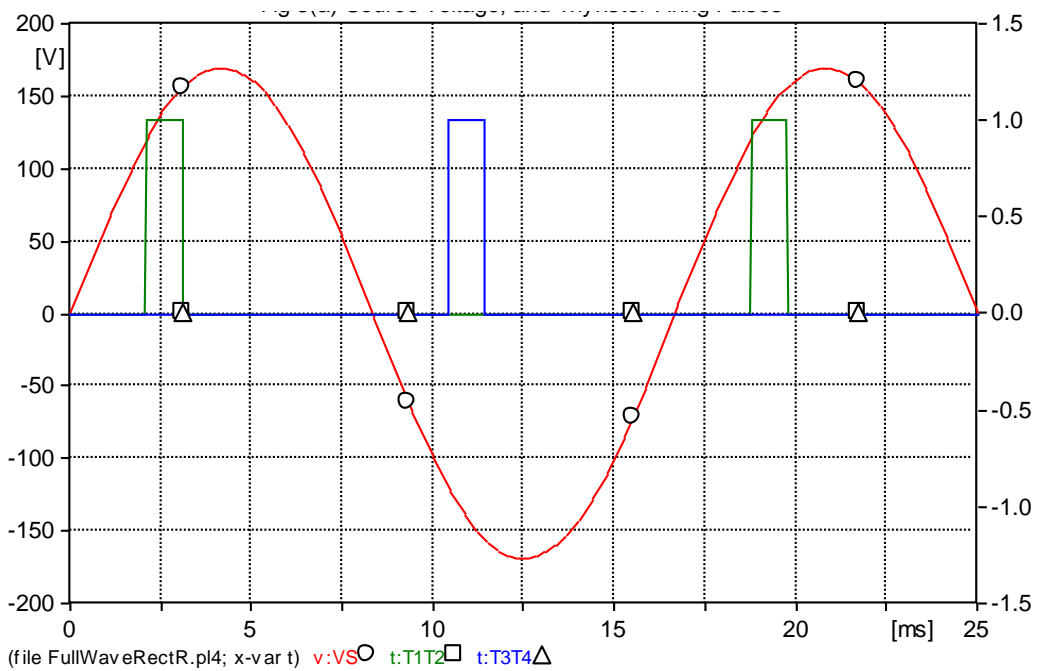

Figure 3a. Source voltage and firing pulses

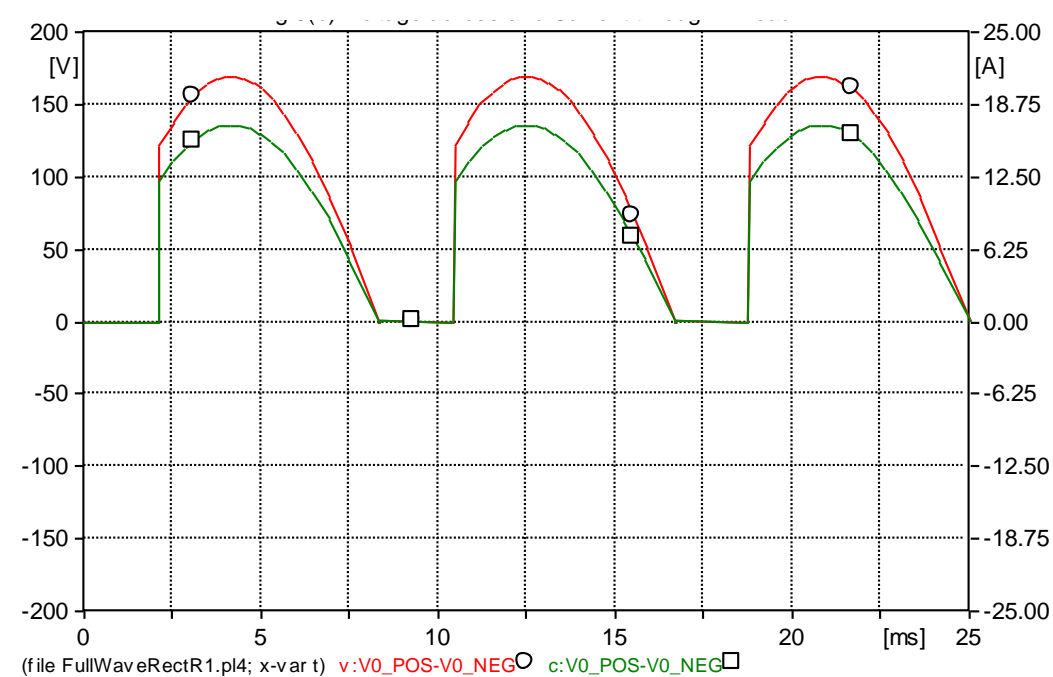

Figure 3b. Load voltage and current for purely resistive load

The output voltage (plotted as v) and output current (plotted as c) are shown in Figure 3b. The thyristor that is turned on at $\alpha$ is turned off at $\pi$ and the thyristor that is turned on at $\pi+\alpha$ is turned off at $2 \pi$. During positive half cycle of the source voltage thyristor pair T1 and T2 are turned on after the instant of firing pulse and are turned off when the current becomes zero. Thyristor turn off process is known as commutation. Similar is true for thyristor pair T3 and T4 during negative half cycle.

The average output voltage Vo and the average load current Io can be given as follows [5]-[7]:

$V_{0}=\frac{1}{2 \pi}\left[\int_{\alpha}^{\pi} V m \sin \omega \mathrm{t} d(\omega \mathrm{t})+\int_{\pi+\alpha}^{2 \pi} \operatorname{Vm} \sin \omega \mathrm{t} d(\omega \mathrm{t})\right]$

After solving we get:

$\mathrm{Vo}=\frac{\mathrm{Vm}}{\pi}(1+\cos \alpha)$

and the average load current can be given as:

Io $=\frac{\text { Vo }}{R}$

From equations (2) and (3), it can be seen that the maximum value of Vo and hence of Io occurs when $\cos \alpha=1$ i.e. $\alpha=0^{0}$.

The firing angle may thus be defined as the angle corresponding to the duration between the instant of triggering that gives largest average output voltage to the instant that gives any desired average output voltage.

\section{Rectifier With R And L Load}

A single phase controlled full-wave bridge rectifier feeding a RL load is shown is shown in Figure 4. The output waveform for this circuit depends on the value of the inductance, L, and the firing angle, $\alpha$. 


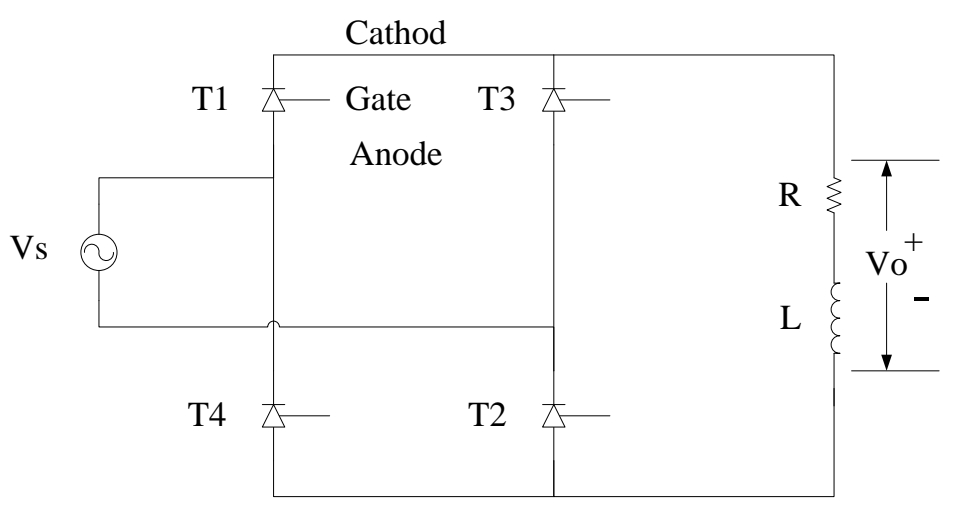

Figure 4. Single-phase full-wave bridge rectifier with $\mathrm{R}$ and $\mathrm{L}$ load

Since, the current cannot change instantaneously in an inductor; thyristor T1 and T2 will continue to conduct even after the voltage zero until the current becomes zero. If the value of inductance is large, T1 and T2 may not turn off at all until thyristors T3 and T4 is fired. Firing of T3 and T4 reverse biases and turns T1 and T2 off. The load current will shift from pair T1 and T2 to pair T3 and T4.

The voltage and current waveforms for an arbitrary RL load are shown in Figure 5. The load voltage Vo becomes equal to the source voltage Vs immediately after thyristors are fired. However, because of the load inductance, the current starts rising gradually from its zero value and attains maximum value after sometime depending upon the value of inductor. It can be seen that at $8.33 \mathrm{~ms}$ i.e. $\pi$ radian $\left(180^{\circ}\right)$, Io is not zero even though Vo is zero. At some angle $\beta(9.3 \mathrm{~ms})$, Io reduces to zero and thyristors T1 and T2 turned off. During the period between $\omega t=\pi$ and $\omega t=\beta$, i.e. when the voltage is negative and the current is positive, the magnetic energy stored in the inductor is delivered back to the supply. After $\omega t=\beta, V_{0}=0$ and $I_{0}=0$. Angle $\beta$ is called extinction angle. Thus, the conduction angle y can be given as [5]-[7]: $y=(\beta-\alpha)$

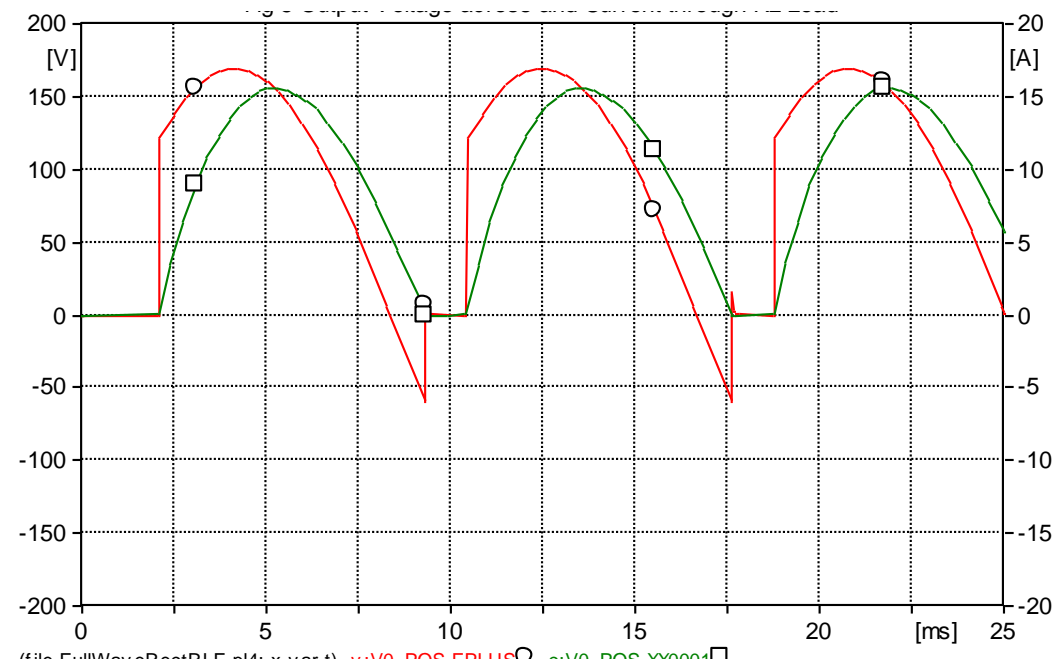

Figure 5. Load voltage and current for resistive and inductive load

It can be seen from Fig 5 that the output current is zero when $\omega t=\alpha$ and $\omega t=\beta$. If the inductance value is large, output current becomes continuous and comparatively ripple free.

The average output voltage Vo can be given as below [5]-[7]:

$\mathrm{Vo}=\frac{2 \mathrm{Vm}}{\pi} \cos \alpha$

IV. Rectifier With R, L, And E Load

A single phase controlled full-wave bridge rectifier feeding a RLE load is shown in Figure 6. Voltage E corresponds to a battery emf or a back emf of a dc motor. Thyristor pair T1 and T2 is fired simultaneously at $\alpha$ while the pair T3 and T4 are fired after $\pi$ radians in each cycle. When pair T1 and T2 is ON, the output voltage is same as the supply voltage. When the pair T1 and T2 is OFF and pair T3 and T4 are not turned ON yet, the output voltage is equal to emf E. Figure 7 shows the output voltage and current waveforms. The presence of a 
voltage source in the load tends to reverse bias the thyristor during the period when $\omega t=0$ and $\omega t=\alpha$. The thyristor will not turn on for a firing angle smaller than a certain value called critical angle, $\alpha_{c}$, can be given as [5]-[7]:

$\alpha_{\mathrm{c}}=\sin ^{-1}(\mathrm{E} / \mathrm{Vm})$

In this paper, for $\mathrm{E}=50 \mathrm{~V}$ and $\mathrm{Vm}=\sqrt{ } 2 * 120 \mathrm{~V}=169.71 \mathrm{~V}, \alpha_{\mathrm{c}}=17.14^{0}$. Since a firing angle of $45^{0}$ is used, there is no problem for thyristor to turn on.

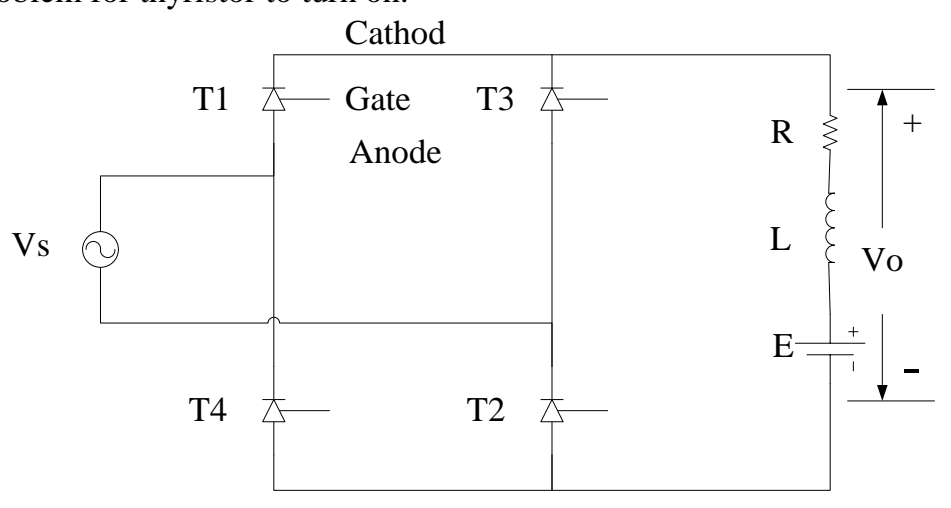

Figure 6. Single-phase full-wave bridge rectifier with R, L, and E load

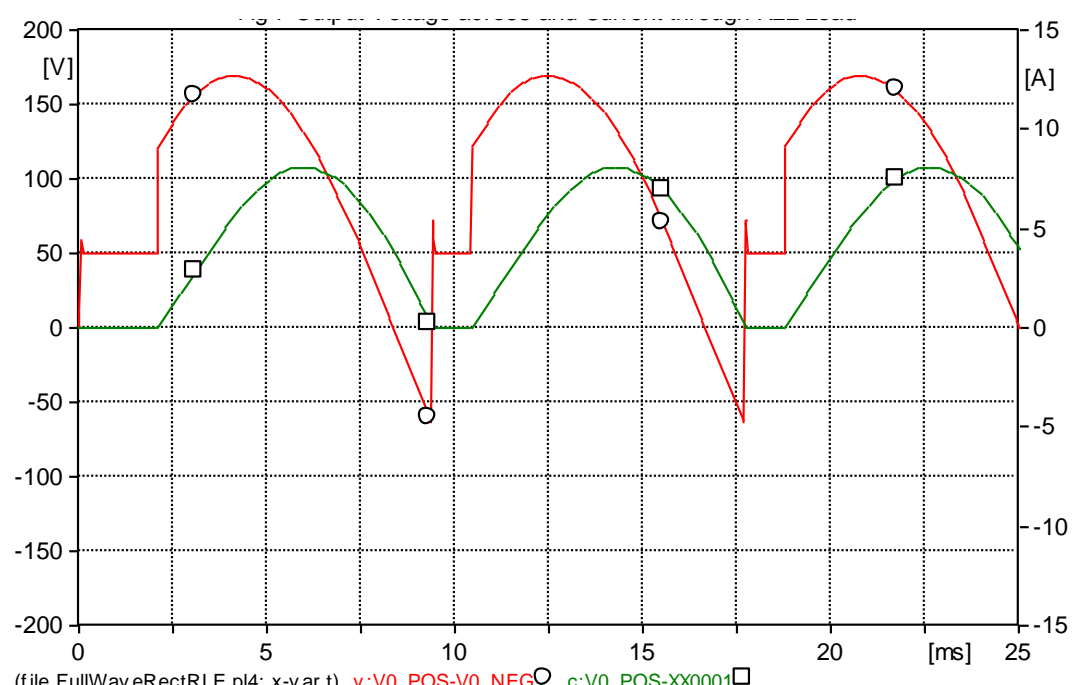

Figure 7. Load voltage and current for resistive, inductive, and emf load

The average value of the output voltage is given below [5]-[7]:

$\mathrm{Vo}=\frac{2 \mathrm{Vm}}{\pi} \cos \alpha$

\section{Results}

The variation of output voltage, Vo, with respect to firing angle $\alpha$ is plotted in Fig. 8. It can be noted that the output voltage is positive until the firing angle is less than $\pi / 2\left(90^{\circ}\right)$ and the output voltage is negative for values of $\alpha$ greater than $\pi / 2$. The operation of the converter takes two different forms. For values $\alpha$ smaller than $\pi / 2$, the converter operates as a rectifier. During this operation power flows from the supply to the load. But, if $\alpha$ is greater than $\pi / 2$ and the load circuit emf $\mathrm{E}$ is reversed, it is possible to transfer the dc power from battery or a running dc motor to the ac supply as ac power. This is equivalent to inversion. Thus, the same converter can operate as a rectifier as well as an inverter depending upon the value of $\alpha$ and the polarity of the dc source. The converter operating as an inverter makes use of the line voltage for commutation. Therefore, it is called line-commutated inverter. 


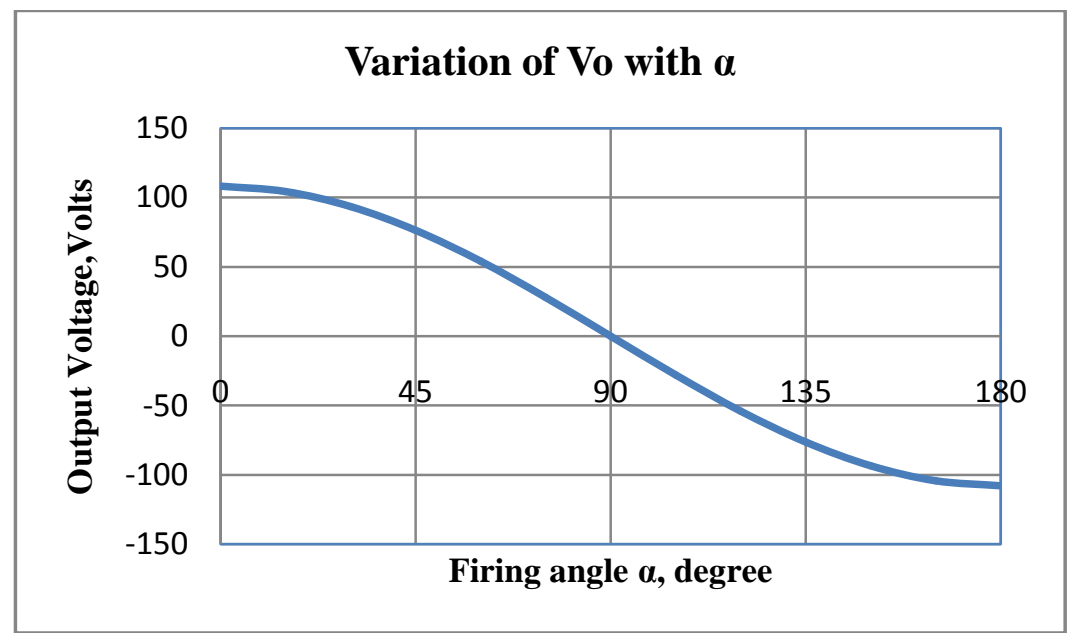

Figure 8. Variation of output voltage with firing angle

From Fig. 8 a table as shown below can be created. The TABLE 1 below shows an interesting relationship between firing angle, $\alpha$, and output voltage, Vo.

Table 1. Results

\begin{tabular}{|c|c|}
\hline Firing Angle & Output Voltage \\
\hline $0^{\circ}$ & $2 \mathrm{Vm} / \pi$ \\
\hline $60^{\circ}$ & $\mathrm{Vm} / \pi$ \\
\hline $90^{\circ}$ & 0 \\
\hline $120^{\circ}$ & $-\mathrm{Vm} / \pi$ \\
\hline $180^{\circ}$ & $-2 \mathrm{Vm} / \pi$ \\
\hline
\end{tabular}

In rectifier operation, the average value of output voltage Vo must be greater than the load circuit emf $\mathrm{E}$, while during inverter operation, the load circuit emf must be greater than the average value of the output voltage. Implementation of the inverter circuit is not presented in this paper and is left as a future work.

\section{Conclusion}

Single-phase full-wave controlled bridge rectifier with thyristor was implemented successfully in ATP. It was noted that the average value of output voltage is a function of firing angle. Thus, by controlling the firing angle, the output voltage can be controlled effectively. This research will help seniors, graduate students, and design engineers to understand the modeling and working principle of ac to dc converters i.e. rectifiers.

\section{References}

[1] A. M. Trzynadlowski, Introduction to modern power electronics (New Jersey: John Wiley \& Sons, Inc, 2010)

[2] B. Wangsilabatra, and T. Suksri, Phase control thyristor based soft-starter for a grid connected induction generator for wind turbine system, International Conf. on Control, Automation and Systems, Kintex, Korea 2010, 529-534

[3] B.R. Pelly, Thyristor phase-controlled converters and cycloconverters-operation, control, and performance (USA: John Wiley \& Sons Inc, 1971)

[4] http://emtp.org, accessed September 2012

[5] N. Mohan, T. M. Undeland, and W. P. Robbins, Power electronics-converters, applications, and design (USA: John Wiley \& Sons Inc, 1995)

[6] T. H. Barton, Rectifiers, cycloconverters, and AC controllers (New York: Oxford University Press, 1994)

[7] B. K. Bose, Power Electronics and Variable Frequency Drives-Technology and Application (New Jersey: IEEE Press, 1997) 